\title{
The Lexile Leap: Consequences for Foundational Skills and Accountability Achievement
}

\author{
David D. Paige ${ }^{1, *}$, William H. Rupley ${ }^{2}$, Theresa Magpuri-Lavell ${ }^{3}$ \\ ${ }^{1}$ Annsley Frazier Thornton School of Education, Bellarmine University, USA \\ ${ }^{2}$ Department of Teaching, Learning and Culture, College of Education and Human Development, Texas A\&M University, USA \\ ${ }^{3}$ Sandra Dunagan Deal Center for Early Language and Literacy, Georgia College, USA
}

Copyright $\bigcirc 2019$ by authors, all rights reserved. Authors agree that this article remains permanently open access under the terms of the Creative Commons Attribution License 4.0 International License

\begin{abstract}
Foundational skills are important to reading success. Additionally, U.S. Core Reading Standards recommend text complexity grade-bands extending from second- through twelfth-grade as a measure of reading growth. The idea means that students must increase their reading skills as they progress across grades and that text complexity offers a reasonable metric for gauging such growth. A challenge with the text-complexity bands is both their breadth and their large increase between thirdand fourth-grade. We present a text-complexity heuristic mapping growth in foundational skills across the elementary grades that provides a more fine-grained perspective for tracking reading development. We next present empirical evidence supporting the heuristic, which shows that students who reach foundational skill criteria by the end of third-grade are much more likely to achieve end-of-year reading proficiency than peers who are less-than-proficient readers.
\end{abstract}

Keywords Foundational Reading Skills, Reading Achievement, Early Literacy Development

\section{Introduction}

Again, the results are the continuation of a weary story regarding the national reading achievement of fourth graders in the United States. The bi-annual National Assessment of Educational Progress [1] report once more shows that close to two-thirds of fourth-grade students are reading at less than proficient levels, results that are emblematic of reading outcomes stubbornly resistant to improvement [2]. Despite the efforts of both hard-working teachers and administrators, these numbers point toward an unacceptable percentage of students who are failing to acquire proficient foundational reading skills. In this article, we offer a heuristic for interpreting students' foundational skill development, evidence of reading foundational skill importance to proficient achievement on a state accountability assessment, and procedures to monitor students in their development and acquisition of reading foundational skills.

\subsection{Revisiting the National Reading Panel Report}

An overview statement by the National Reading Panel [2] (NRP) noted:

The conclusion drawn is that growth in word-reading skills is strongly enhanced by systematic phonics instruction when compared to non-phonics instruction for kindergartners and 1st graders as well as for older struggling readers. Growth in reading comprehension is also boosted by systematic phonics instruction for younger students and reading disabled students. ( $\mathrm{p}$. 2-94).

In light of this statement, what we heard while in attendance at a recent conference was disappointing to say the least. The workshop facilitator asked how many of those present teachers had taken a course in phonics instruction during either their undergraduate or graduate education. One would assume most everyone, of course? However, of the 33 teachers in attendance, only two raised their hands. While we would never hold this informal survey as representative of those teachers in attendance (some of us just don't like raising our hands, do we?), we do wonder how many teachers have not been trained in teaching systematic, letter-sound understanding and reading fluency. Increasing evidence suggests that teacher licensure programs poorly prepare elementary teachers in systematic phonics instruction [3, 4]. This results in low levels of core reading knowledge among those most important to its successful reading acquisition in young students [5]. On the heels of this question, the facilitator then asked the audience "Why do kids get stuck at certain reading levels, or in other words why do students plateau in their reading development?" The response from the audience was a deafening silence. While there are various 
answers to this question, in this article we take the view and provide evidence that foundational reading skills must be firmly in place if children, particularly those at-risk for reading failure, are to succeed in core reading assessments. With this in mind, just how do beginning readers acquire the ability to read words quickly?

\subsection{The Theory of Orthographic Mapping}

Torgesen [6] has called orthographic mapping "the most complete current theory of how children form sight word representations" (p. 36). Orthographic mapping explains how readers come to quickly form retrievable and accurate word representations in memory [7]. Through the process of matching letters and letter patterns to their phonemic constituents, the reader blends the sounds into a spoken word that is quickly matched to a familiar, contextually appropriate representation from the reader's mental lexicon $[8,9]$. To enable this mapping process, the reader must have the requisite abilities to isolate and manipulate phonemes within words, possess letter-sound understanding, and have sufficient phonological memory resources to temporarily retain a word's phonology while syntactic and semantic features are being retrieved $[10,11]$. Development of these reading sub-skills comprise the orthographic mapping process where the reader is able to self-learn the hundreds of letter-sound combinations contained within written English that are crucial in the development of a deep sight word inventory [12, 13]. While the self-learning hypothesis recognizes the phonological process as critical [14], it is orthographic mapping that explains how phonemic awareness enables the reader to use emerging letter-sound understanding as a mechanism for word learning. As few children easily acquire phonemic awareness, most need explicit instruction $[15,16]$.

\subsection{Word Reading Development}

Ehri [17] has identified developmental phases that describe how the reader comes to identify words quickly and accurately. In the pre-alphabetic phase, the reader relies completely on visual cue reading. Thus, the reader uses a salient visual feature of the word as a link to its pronunciation. In the partial alphabetic phase, readers become aware of sounds in words as they begin to connect some letters in a word to the sounds represented in their pronunciation. Ehri notes that partial cue reading relies heavily on the initial consonant in the word to connect it to its pronunciation. Complete connections between all letters in the word and their phonemes takes place in the full alphabetic phase that enables the reader to arrive at a correct pronunciation. Readers in this phase are now accurate readers and can leverage their knowledge of letter-sound combinations to decode unknown words. This stage is marked by fully mapped orthographic representations that can be quickly and accurately recalled [18].

\subsection{Text Complexity}

Complexity is a characteristic of a written text, while difficulty refers to a reader's ability to proficiently read and comprehend a particular text. Within the framework of Core Reading Standards [19] (CRS), students' reading ability is scaffolded so students completing the twelfth-grade will be able to fluently read and comprehend a text in the Lexile ${ }^{\odot}$ range of 1250L -1325L [19]. To achieve such competence, reading instruction must begin in the early elementary grades with a firm foundation of relevant word recognition and fluency skills that set the student on a successful trajectory to reading achievement.

\subsection{Understanding Lexile ${ }^{\odot}$}

The Lexile ${ }^{\odot}$ metric determines both a student's developmental reading level and the complexity of a particular text. Lexile ${ }^{\mathbb{C}}$ levels can range from below $0 \mathrm{~L}$ (-200L for example) to approximately 2000L. Klare [20] hypothesized that the frequencies at which words appear in text vary along a familiar-to-rare continuum. Based on Klare's idea, Lexile ${ }^{\mathbb{O}}$ measures vocabulary (semantic) frequency and sentence length (syntactic components) using a 300 million-word corpus to arrive at a numeric level of complexity. Additional characteristics such as the number of letters and syllables within a word are also proxies for word frequency, while sentence length is an acceptable estimate for the demand that syntax can place on working memory [21]. Because Lexile ${ }^{\odot}$ deconstructs text into 125-word chunks, the precision of syntactic and semantic estimates is increased. Finally, the Lexile ${ }^{\mathscr{C}}$ metric offers increased precision over typical grade- and age-based text estimates because it uses an equal-interval scale, meaning for example, that the 20-point difference between $200 \mathrm{~L}$ and $220 \mathrm{~L}$ is the same as the 20 -point difference between 1120L and 1140L [27].

\subsection{Lexile ${ }^{\odot}$ Concerns}

Foorman [22] points out three areas of concern regarding what Lexile ${ }^{\mathscr{C}}$ does not measure. First, readability is used in a circular process to sort passages by grade-level, and then as a measure to determine grade-level reading. Also, passages can be manipulated to adjust grade-level that may create validity issues regarding comprehension. Second, the surface features used to calculate readability do not capture some linguistic features such as the continuum of concrete-to-abstract words, the author's use of anaphora, text structure, and the discourse features of text coherence and cohesion [23]. Third, Foorman points out that certain literacy genres such as poetry and early-grade texts are particularly difficult to grade using readability formulas. Generally speaking, as sentence length grows, so does 
syntactic complexity; however, these relationships may vary across a text and not be detected by Lexile ${ }^{\mathcal{O}}$ [24]. Lexile ${ }^{\mathscr{O}}$ has also been found to not always capture syntactic differences in text $[25,26]$. Core standards have recognized many of these limitations by recommending that human raters conduct a qualitative evaluation of text. Overall, we think Lexile ${ }^{\mathscr{O}}$ remains an important tool that can assist teachers as they scaffold text across grades to ensure students are building their reading with increasingly complex texts. Let's now consider the text-complexity grade bands contained within the Common Core Standards [19] (CCS), and the Lexile ${ }^{\mathscr{O}}$ Leap that a student must summit to remain an adequately developing reader.

\subsection{The Lexile $^{\odot}$ Leap}

How do foundational reading skills interact with text complexity to scaffold reading development? To make explicit the between-grades increase in textual demands, the CCS constructed text-complexity grade-bands using the Lexile ${ }^{\odot}$ metric. Bands were promulgated in the original 2010 Standards document and later revised upward [27].
The levels reflect a $2 \mathrm{nd} / 3$ rd-grade lower complexity band of $420 \mathrm{~L}$ and an upper band of $820 \mathrm{~L}$. Of significant note is the dramatic increase in Lexile when moving from the grade 2-3 to 3-4 bands where the lower complexity level increases from $420 \mathrm{~L}$ to $740 \mathrm{~L}$, an increase of $320 \mathrm{~L}$ or $76 \%$. We call this increase the Lexile ${ }^{\odot}$ Leap and it has serious instructional implications. When fundamental reading skills are ignored or inadequately developed in the early elementary grades many students will struggle to competently read later elementary texts.

For elementary teachers tasked with preparing students with critical foundational reading skills, the challenge of summiting the end-of-third-grade Lexile ${ }^{\mathscr{O}}$ Leap cannot be ignored. We believe that teachers must be explicitly aware of the reading sub-skills embedded within the developmental path that guides reading growth in their students. Instructional attention to the proper development of these skills is required if each student is to be adequately prepared to summit the Leap as they transition from thirdto fourth-grade. The PATH heuristic in Figure 1 helps to visualize both the Lexile ${ }^{\mathbb{O}}$ Leap and the developmental trajectory of skills across grade levels.

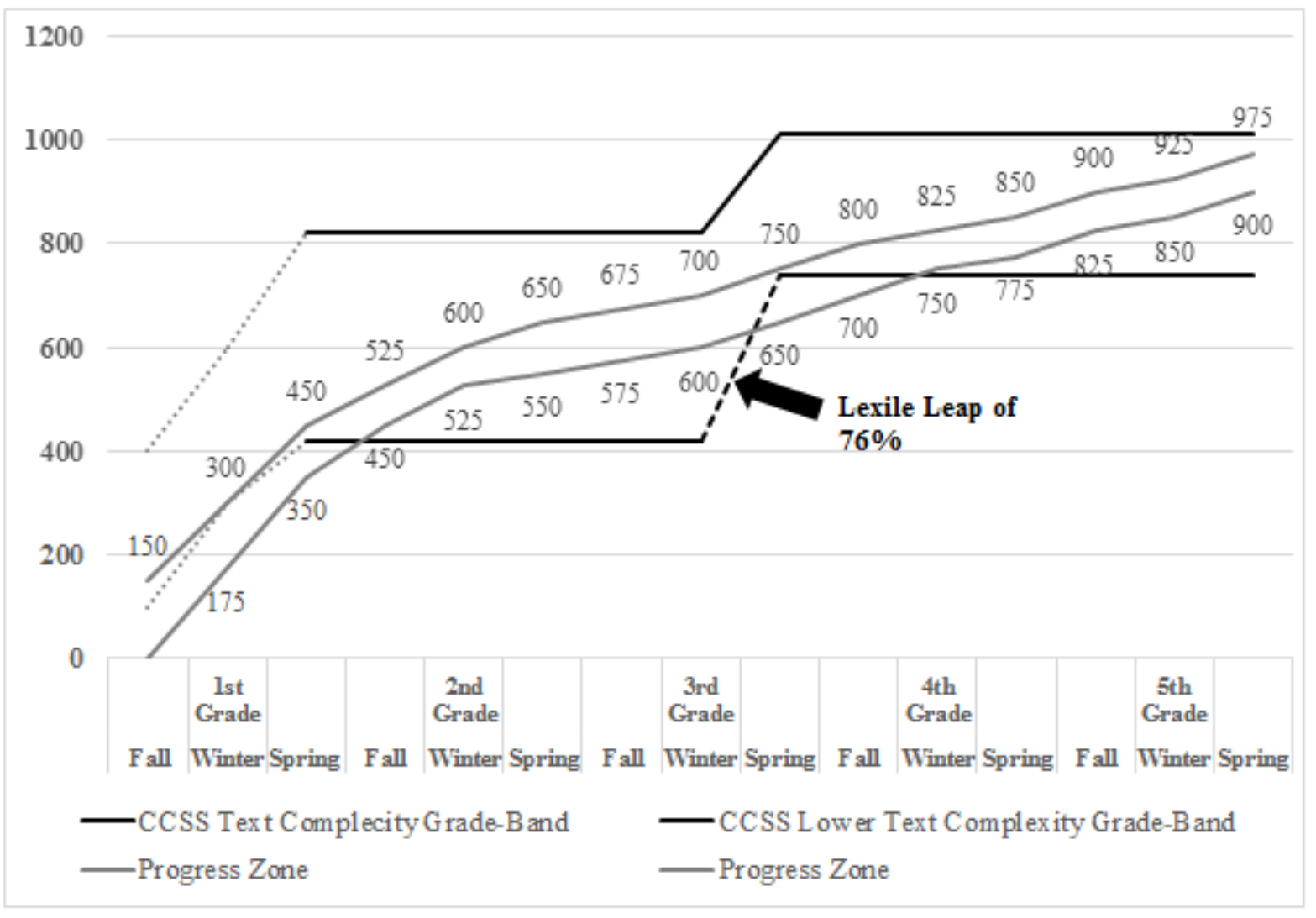

Figure 1. PATH Heuristic Showing Adequate Progress Zone, Grades $1-5$. 


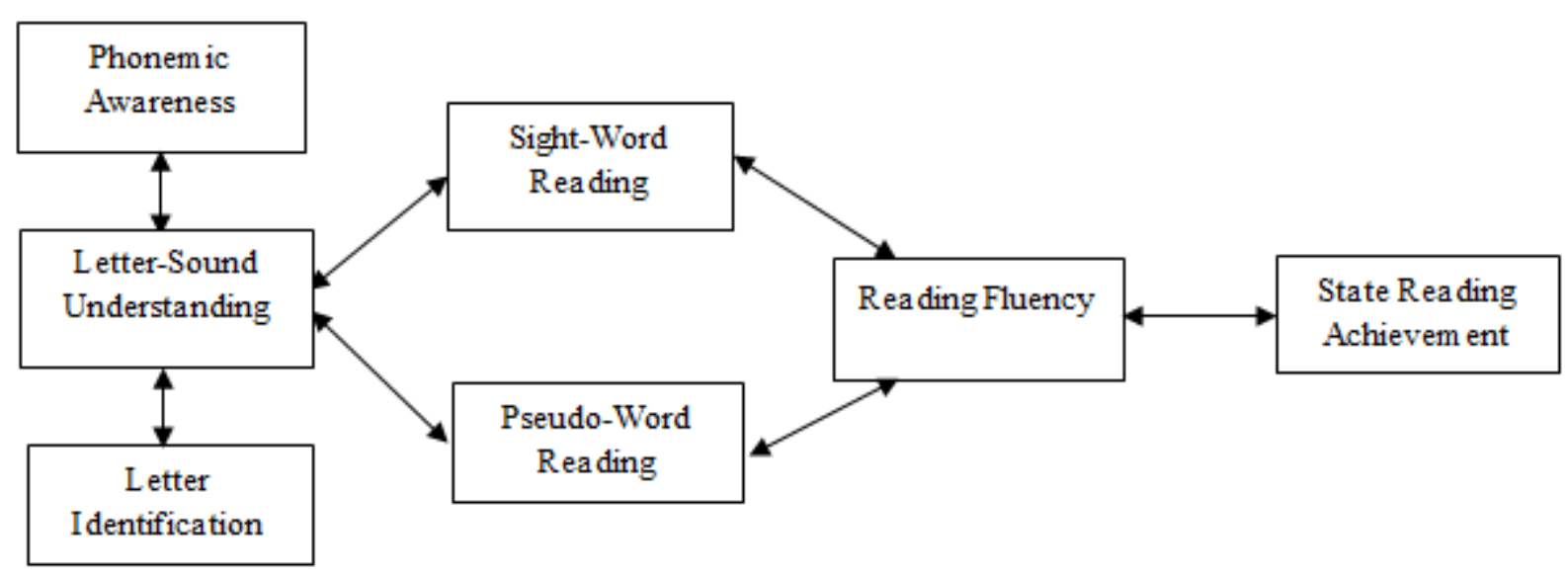

Figure 2. Theoretical Model Linking Reading Sub-Skills to State Reading Achievement

\subsection{The PATH to Reading Achievement}

The reading achievement PATH is founded upon strong evidence presented by Smith and Williamson [28] linking reading growth to text complexity [29]. While the PATH is framed within the lower and upper text complexity bands recommended by the CCS, the value of the PATH is that it specifies for the teacher an explicit lower- and upper-text-complexity progress path by grade and time-of-year that when attained, insures the student remains on a viable route to reading success. The PATH reflects achievement based on oral reading fluency, which has been shown to predict state reading attainment [30]. For example, looking at Figure 2, one can see that each grade has three points anchoring time-of-year (TOY) Lexile boundaries. For example, the third-grade TOY point for fall suggests students be able to read texts within 575L to $675 \mathrm{~L}$. Moving to the middle TOY reflects that text complexity attainment is $600 \mathrm{~L}$ to $700 \mathrm{~L}$ while the spring TOY complexity increases to $650 \mathrm{~L}$ to $750 \mathrm{~L}$. Across the PATH the TOY attainment points are meant to be viewed as minimum guidelines for reading development. Students who struggle to read text within these complexity levels are at-risk for poor reading outcomes and are highly likely to struggle with summiting the Lexile $^{\odot}$ Leap as they matriculate to fourth-grade.

\subsection{Sub-skill Development Is Important}

We think it is necessary for teachers to know, through adequate formative assessment, the extent to which students are acquiring the necessary reading sub-skills that fuel orthographic mapping, which supports adequate reading development across the PATH that ultimately facilitates reading comprehension. We point out here that not all agree that the role of phonics is central to effective reading development. Whole-language adherents believe that reading instruction should use a holistic and social developmental approach based on the reader's response to literature $[30,31]$. However, reading theorists from the cognitive sciences maintain that efficient decoding and word reading processes enable the reader to better focus their attentional resources on comprehension processing activities that facilitate text understanding [32, 33, 34]. For example, do students possess full letter identification knowledge in kindergarten? Can they isolate and manipulate phonemes occurring at the beginning, ending, and medial positions of words? Is their letter-sound understanding commensurate with their sight-word knowledge that is necessary to support the fluent reading of texts at the appropriate complexity level to progress along the PATH? Do they possess requisite sub-skills and simply need more experience and practice to fluently read connected text? And of course, do readers attend to the text sufficiently to extract understanding? If these sub-skills are not developed to mastery level, then students will benefit little, if at all, from the teaching of comprehension strategies as they use most of their attentional resources on decoding words [35].

This study investigates the development of foundational reading skills and their role in reading achievement. Two research questions guide this study:

RQ1: To what extent is spelling knowledge, sight- and pseudo-word reading, and reading fluency developed in end-of-year third-grade students?

RQ 2: What is the likelihood that a student proficient in foundational reading skills would achieve proficiency on a state-administered reading test?

To assess reading development within the PATH, we conducted a study of third-grade readers that measured the contribution of foundational skills at levels suggested within the progress path to end-of-year state reading achievement. The study was part of a large-scale project designed to build and grow teacher declarative knowledge and pedagogical capacity. Guiding our inquiry of reading success is the model shown in Figure 2 where letter identification and phonemic awareness facilitate letter-sound understanding, which facilitates sight- and pseudo-word reading that then supports reading fluency. Reading fluency is then hypothesized to affect state reading achievement [36]. We point out that appropriate 
letter-sound understanding is the result of explicit and systematic phonics instruction, identified by the National Reading Panel [1] as one of the Big Five reading processes.

\section{Method}

\subsection{District Description}

The study took place within a large, urban district in the Southeast U.S. where $64 \%$ of students received free- or reduced-priced lunch. Approximately $49 \%$ of students were of Caucasian ethnicity, $37 \%$ were African-American, and $14 \%$ were of other ethnicities. About $4.8 \%$ of students participated in English as a second language program, while about $12.5 \%$ of students received special education services.

\subsection{The University Literacy Project}

At the request of district leadership, University reading faculty designed and oversaw implementation of an initial one-year academy to provide professional development for $\mathrm{K}-3$ reading teachers in the core reading knowledge and instructional skills necessary to diagnose, differentiate, and deliver reading instruction for each student. The ULP began in the 19 lowest performing schools in the district and teachers volunteered to attend two graduate reading classes, one in the fall and another in the spring. Each course required 45 hours of class time for which teachers received 3 hours of graduate credit at no cost. The curriculum covered principles of reading theory, assessment, and research-based, culturally responsive strategies to facilitate phonological awareness, letter-sound understanding, reading fluency, vocabulary understanding, and comprehension. After the first year of the ULP excitement had grown among teachers who requested a second year to further extend what they had learned. Over the course of what became a four-year project, nearly half $(47 \%)$ of all teachers volunteering for the first year completed the second year of training.

The ULP (Figure 3) also incorporated a support component that focused on the effective training of literacy coaches and included a principal's cohort to help school leaders identify, share, and implement productive methods for supporting faculty. As the ULP matured, the reading curriculum was refined based on participant feedback and effectiveness. In the $3^{\text {rd }}$ year, the third author of this study became embedded in the district as a scholar-in-residence. This allowed full-time mentoring and involvement with teachers, coaches, and teacher-trainers who were becoming literacy leaders with deep core and practice knowledge as a result of their participation in the ULP. As the ULP progressed, a question of interest among district leaders was whether or not foundational skills instruction had an effect on students' end-of-year accountability test results?

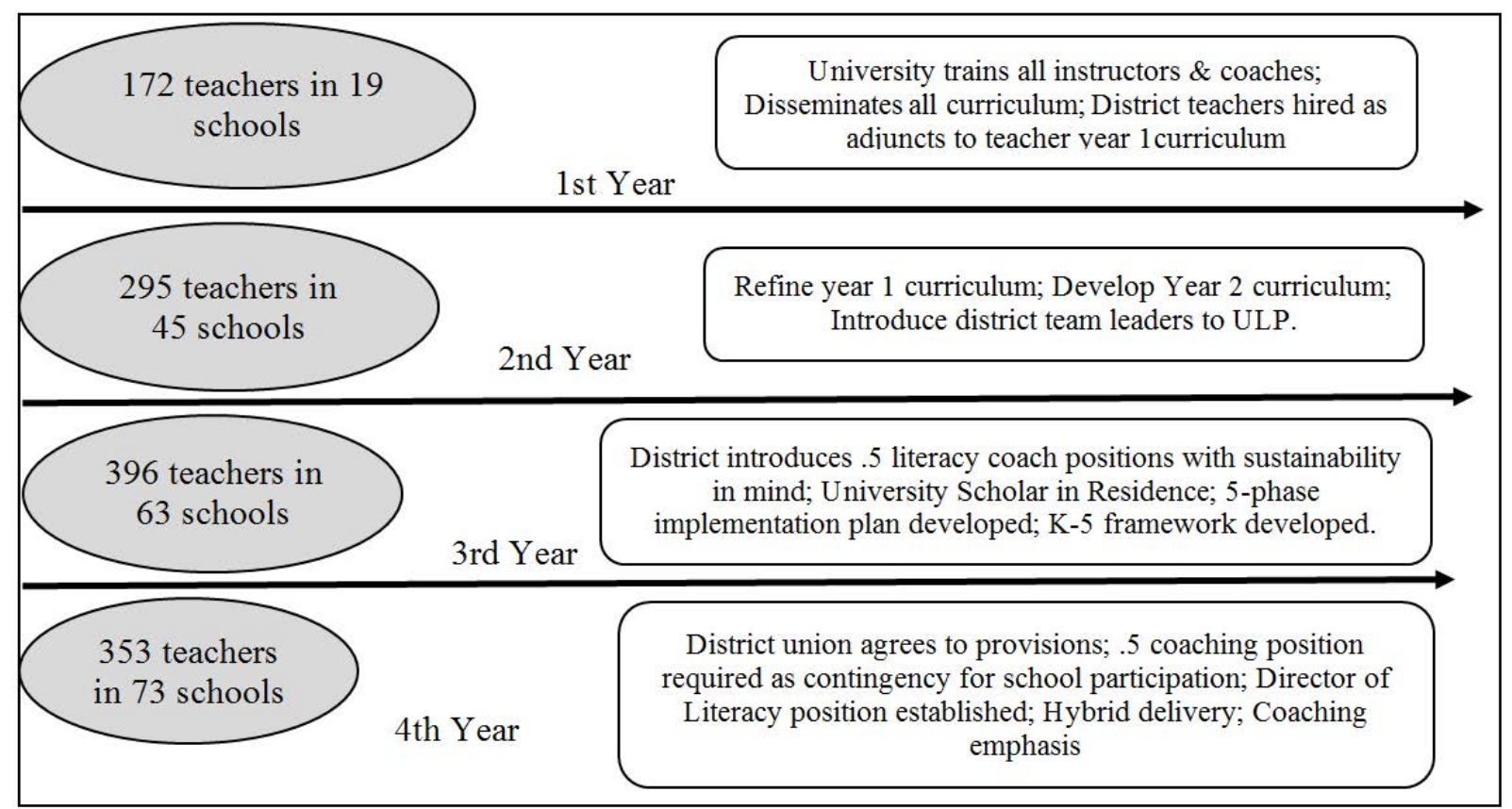

Figure 3. Capacity-Building by Year 


\subsection{Students}

In the 3rd year of the ULP, we assessed the reading sub-skills of 1,064 end-of-year third grade students. These students attended 31 elementary schools in the district. The students were instructed by 52 different teachers, all of whom were participating in the ULP. The students came from a variety of ethnicities and included $46.9 \%$, who were African-American, 33.2\% Caucasian, 12.4\% Hispanic, while the remaining $7.5 \%$ were of several other ethnicities. The students resided in nearly three dozen different census tracks with $44.2 \% \quad(s d=13.3)$ living in poverty circumstances. Of the students attending the study schools, $12.0 \%$ were English language learners and $13.7 \%$ were diagnosed with a mild/moderate learning disability. At the time of the study, the average age of all students was 8 years, 8 months.

\subsection{Assessing Students}

Students were assessed on five measures testing letter-sound understanding, word- and pseudo-word reading, reading fluency, and state reading achievement.

Letter-sound understanding. The Developmental Spelling Assessment Screener (DSA) is a 20-item spelling test that is group administered [37]. Spelling development has been found to accurately reflect what a student understands about the letter-to-sound relationships necessary to decode words that results from effective phonics instruction [38, 39]. Knowledge of these relationships develops in stages and the DSA identifies the most likely spelling stage of a student from among four that include letter-naming, within-word, syllable-juncture, and derivational constancy. Results of the DSA are highly useful to teachers skilled in phonics instruction as they specifically identify what a student understands and has yet to learn about decoding words. Students spell five words within each stage so that a score of 0-5 indicates attainment at the letter-naming stage, 6-10 at the within-word stage, 11-15 signifies the syllable juncture stage, and 16-20 indicates derivational stage knowledge. The DSA author reports test-retest reliability of .97 to .98 .

Word reading. The Test of Word Reading Efficiency-2 ([40] (TOWRE-2) is a norm-referenced, standardized test consisting of two subtests. The word reading efficiency subtest contains 108 regular word items while the pseudo-word efficiency subtest contains 88 items. Pseudo-words contain spelling patterns that are not used in English but are pronounceable using letter-sound understanding and as such, measure the ability of the reader to apply what they understand about letter-sound correspondences without interference from words the reader may know by sight. Both tests give students 45 seconds to read aloud as many increasingly complex words as possible. Test-retest reliability coefficients for the assessed age group equal .92 and .87 for the sight- and pseudo-word tests respectively.

Reading fluency. All students read aloud a curriculum-based, narrative text that is measured in the $700 \mathrm{~L}$ to $750 \mathrm{~L}$ range. Readability was also assessed using Coh-Metrix [41] for which the text rated high in narrativity, syntactic simplicity, and word concreteness while measuring low in referential and deep cohesion. Students were recorded while they read the text aloud for up to three minutes. Test administrators recorded reading miscues consisting of omissions, insertions, mispronunciations, and word reversals. At the end of the reading, the number of words read and word reading miscues were recorded. For each reader we subtracted reading miscues from the number of words read, and divided the score by the amount of time the student took to read the passage, which resulted in a fluency score representing the number of words read correctly per minute. Curriculum-based measures have been found to exhibit high reliability [42, 43]. We conducted a split-half reliability for fluency resulting in a Pearson's $r=.991$, suggesting exceptionally good reliability.

State reading achievement. Reading subtest scores from the state-required reading test (SRT) were used to measure state reading achievement. These tests are not widely considered to be a strict test of reading comprehension; rather, they include a variety of reading tasks to measure attainment of the state reading standards. While some tasks include the identification of the main idea and supporting details of a passage, arranging story events in chronological order, and identifying the author's purpose, others tasks, such as organizing and categorizing information draw on skills that are less closely related to simple comprehension. Some authors maintain that attainment on SRTs can be reliant on a student's background and global knowledge, the extent of which can greatly affect the understanding constructed by a student [44]. Because such tests assess both reading comprehension, as well as broader skills, we refer to them as instruments that measure academic achievement through reading. While this is a nuanced distinction, it recognizes that not all in the reading field acknowledge these tests as strict assessments of reading comprehension. The SRT was administered by the school district and is a blended criterion and norm-referenced test with multiple choice and constructed-response items. The SRT was constructed using Lexile ${ }^{\mathcal{C}}$ to assess the text complexity of test content $[45,46]$. SRT scores range from 100 to 300 with scores in the present study ranging from 154 to 287 . Third grade students achieving scores $\geq 210$ are considered proficient while those scoring below are less than proficient. Reliability for the SRT has been reported by the test makers as Cronbach's alpha $=.89$. 


\section{Results}

\subsection{Question One}

The first question asked the extent to which spelling, sight- and pseudo-word reading, and fluency were developed in our sample of third-grade readers who received reading instruction from the teachers who were trained in the ULP. Table 1 shows the average scores and percentiles for each of the assessments. The DSA screener resulted in a mean of 8.08 and reflects attainment in the within-word stage [37]. This score suggests that as a group, students had mastered skills in the letter-naming stage that included beginning and ending consonants and consonant blends, short vowels, long vowels (VCe), and r-controlled vowels. Students were also gaining competence with complex consonants and words with abstract vowel sounds. Both sight-word and pseudo-word reading was measured with the TOWRE-2, which offers the opportunity to compare scores to a national sample. Both sight- and pseudo-word means were commensurate with the 37th percentile. Reading fluency for the group was 76.3 words-correct-per-minute which equates to about the 25th percentile on the Hasbrouck and Tindal [47] norms for end-of-third-grade readers. Finally, the mean SRT score of 199.23 was well below the cut-point of 210 set by the state to indicate reading proficiency. Using logistical regression analysis our model in Figure 3 explained $41 \%$ of the difference in state reading outcomes. What was unexpected was that spelling development had a direct effect on both reading fluency and SRT reading achievement. In total, spelling development, sight-word reading, and reading fluency were similar in their ability to predict state reading achievement (standardized beta coefficients $=$ to 0.361 , 0.365 , and 0.395 respectively), which strongly suggested that all were important.

\subsection{Question Two}

The second research question asked the likelihood that a student proficient in foundational skills would achieve proficiency on the SRT reading test? To answer this, we created a metric we called the Reading Quotient (RQ) by equally weighting the DSA spelling and reading fluency scores. We calculated the RQ for each student and then identified whether or not a student had achieved foundational skills proficiency. Our analysis concluded that $329(31 \%)$ students met our criteria for proficiency in foundational reading skills. We then identified that out of our sample of 1,064 students, 295(27.7\%) had achieved reading proficiency on the SRT reading assessment.

We continued by determining if a student was proficient in foundational skills, what was the likelihood that she/he would also be proficient on the SRT reading test? To determine this, we conducted a crosstab analysis between foundational skills and SRT proficiency. Results in Table 2 revealed a statistically significant chi-square test $\left[\chi^{2}(1)=\right.$ 193.62, $p<.001$ ], a Nagelkerke $R^{2}$ analog $=.220$, and a statistically significant Wald test [Wald $=180.70(1), p$ $<.001]$. The results show that students proficient in foundational skills had a $70 \%$ chance of being proficient on the SRT reading assessment while less-than-proficient in foundational skills had a $20 \%$ chance of SRT proficiency.

Table 1. Means, Standard Deviations, and Percentiles for the Assessed Variables

\begin{tabular}{|c|c|c|c|c|c|}
\hline Percentile & DSA Spelling & Sight-Word Reading & Pseudo-Word Reading & Fluency & SRT \\
\hline 25 th & 5.00 & 49.00 & 18.00 & 50.00 & 186.00 \\
\hline 50 th & 7.00 & 60.00 & 27.00 & 77.67 & 198.00 \\
\hline 75 th & 11.00 & 68.00 & 36.00 & 103.00 & 210.00 \\
\hline Means $(s d)$ & $8.08(4.37)$ & $27.47(12.24)$ & $57.21(16.56)$ & $76.31(36.08)$ & $199.23(23.10)$ \\
\hline \multicolumn{2}{|r|}{ Note. DSA = developmental spelling assessment - screener. SRT = state reading test. Fluency = correct-words-per-minute. } \\
\hline
\end{tabular}

Table 2. Odds of SRT Proficiency When Proficient in Foundational Skills

\begin{tabular}{|c|c|}
\hline Foundational Skills Proficient & \% Attaining SRT Proficiency \\
\hline Yes & 70 \\
\hline No & 20 \\
\hline Note. Odds test $=6.94 . \chi^{2}(1)=193.62, \mathrm{p}<.001 ;$ Nagelkerke $R^{2}$ analog $=.220$. Wald test $[180.70(1), p<.001]$. SRT $=$ state reading test \\
\hline
\end{tabular}




\section{Discussion}

Our findings contribute to the literature base in several ways. First, the Lexile ${ }^{(}$Leap heuristic offers a developmental guide based on text complexity to scaffold reading development. Second, our results provide clear evidence of the importance of foundational reading skills. Third, our study provides clear benchmarks defining adequately developed, end of third-grade foundational reading skills. Fourth, we established a clear relationship between foundational reading skills and proficiency on a standardized, end-of-year state reading assessment.

Overall, the students in our study struggled with foundational reading skills. Our results came after teachers had engaged in intense capacity building, some for a full year, and others for two years. At the end of project year 1 only $9 \%$ of students met our requirements for proficient foundational skills while two years later $31 \%$ had met the criteria, an increase of $244 \%$. A medical analogy for these results would be a pre-treatment survival rate of 9 individuals out of 100, compared to survival rate of 31 out of 100 for those receiving adequate treatment. Thus, increasing the capacity of teachers, coaches, and administrators in fundamental reading knowledge and pedagogy made a promising difference in third-grade reading outcomes. What is clear from our results is that students possessing proficient foundational skills at the levels specified in the PATH resulted in a strong probability that they would score proficient or better on the state reading test.

The evidence supports the idea presented within the PATH heuristic that appropriate end-of-third-grade letter-sound understanding that is well into the within word stage, coupled with attainment of reading fluency at a level of 95 correct-words-per-minute resulted in a strong probability of attaining reading proficiency or better on the state reading assessment. It also supports the notion that these skills must be taught and developed well before a child enters third-grade.

\section{Professional Development}

Our work in districts serving a large percentage of students who struggle with reading has shown that most often elementary teachers neither have the foundational reading knowledge nor are fully trained in the importance and instruction of phonological awareness, letter feature knowledge, decoding, comprehension and fluent reading. This is because they have not been exposed to the theories (e.g., the Simple View, [48]) explaining how these sub-skills develop in a reader to form an efficient word reading system. This means that effective, on-going professional development must take place for all K-5 teachers in the school. This reflects the mindset that each teacher must be knowledgeable and effective regarding reading instruction. Our work in the ULP with over 1,000 teachers supports the idea that when teachers are provided proper training, they become powerful learners and agents for change that greatly benefits their students.

\section{Conclusions}

We suggest that schools incorporate a common set of measures to monitor reading sub-skills development in each student. This is important, first, to ensure that each student is progressing properly in their reading, and if not, the teacher will be aware so the difficulty can be addressed on a timely basis. Second, such a system means that teachers within- and across-grades have the same, intentional understanding of student progress grounded on the student reading attributes that contribute to successful reading. While many schools use standardized growth-based tests that assess attainment of reading standards, such tests are not particularly helpful at identifying development of a student's reading sub-skills. Without a clear understanding of the development of these sub-skills, and of how to appropriately develop them, it is difficult to significantly move reading attainment. This leads to students leaving early elementary grades with fossilized reading skills that are insufficient to read texts of increasing Lexile ${ }^{\mathcal{C}}$ complexity.

\section{REFERENCES}

[1] National Institute of Child Health and Human Development (2000). Report of the National Reading Panel: Teaching children to read: An evidence-based assessment of the scientific research literature on reading and its implications for reading instruction. (NIH Pub. No. 00-4769). Washington, D.C: U.S. Government Printing Office.

[2] U.S. Department of Education, Institute of Education Sciences, National Center for Education Statistics, National Assessment of Education Progress (NAEP), 2017 Reading Assessment. Retrieved from https://nces.ed.gov/nationsrep ortcard/reading/

[3] Binks-Cantrell, E., Washburn, E.K., Joshi. R.M., \& Hougen, M. (2012). Peter Effect in the preparation of reading teachers, Scientific Studies of Reading, 16(6), 526-536. DOI: $10.1080 / 10888438.2011 .601434$

[4] Joshi, R. M., Binks, E., Hougen, M., Dahlgren, M. E., Ocker-Dean, E., \& Smith, D. L., (2009). Why elementary teachers might be inadequately prepared to teach reading. Journal of Learning Disabilities, 42(5), 392-402. DOI $10.1177 / 0022219409338736$

[5] Reutzel, D.R., Dole, J.A., Fawson, P.C., Jones, C.D., Fargo, J.D., et al. (2009). Connecting primary grade teacher knowledge to primary grade student achievement: Developing an evidence-based assessment tool - The literacy instruction knowledge scale (LIKS). Washington, DC: Institute of Education Science. 
[6] Torgesen, J.K. (2004, March). Bringing it all together: From phonemic awareness to fluency. Paper presented at the CORE Literacy Leadership Summit. Retrieved from http://www.fcrr.org/science/pdf/rorgesen/core_pafluency.p df

[7] Ehri, L.C. (2014). Orthographic mapping in the acquisition of sight word reading, spelling memory, and vocabulary learning. Scientific Studies of Reading, 18, 5-21. doi: 10.80/10888438.2013.819356

[8] Ehri, L., \& Wilce, L. (1985). Movement into reading: Is the first stage of printed word learning visual or phonetic? Reading Research Quarterly, 20, 163-179.

[9] Rack, J., Hulme, C., Snowling, M., \& Wightman, J. (1994). The role of phonology in young children learning to read words: The direct-mapping hypothesis. Journal of Experimental Child Psychology, 57(1), 42-71. http://dx.doi.org/10.1006/jecp.1994.1003

[10] Baddeley, A.D. (1992). Working memory. Science, 255, 556-559.

[11] Ehri, L.C. (2005). Learning to read words: Theory, findings, and issues. Scientific Studies of Reading, 9, 167-188. doi: 10.1207/s1532799xssr0902_4

[12] Gough, P.B., \& Hillinger, M.L. (1980). Learning to read: An unnatural act. Annals of Dyslexia, 30(10, 179-196. DOI: 10.1007/BF02653717

[13] Juel, C. (1994). Learning to read and write in one elementary school. New York: Spring- Verlag.

[14] Share, D.L. (1995). Phonological recoding and self-teaching. Sine qua non of reading acquisition. Cognition 55(2), 151-218.

[15] Foorman, B.R., Francis, D.J., Fletcher, J.M., Schatschneider, C. (1998). The role of instruction in learning to read: Preventing failure in at-risk children. Journal of Educational Psychology, 90(1), 37-55.

[16] Phillips, B.M., \& Torgesen, J.K. (2006). Phonemic awareness and reading: Beyond the growth of initial reading accuracy. In D. K. Dickinson \& S. B. Neuman (Eds.), Handbook of early literacy research (Vol. 2) (pp. 101-112). New York: Guilford.

[17] Ehri, L. (1998). Grapheme-phoneme knowledge is essential for learning to read words in English. In J. L. Metsala \& L. C. Ehri (Eds.), Word recognition in beginning literacy (pp. 3-40). Mahwah, NJ: Erlbaum.

[18] LaBerge, D., \& Samuels, S.J. (1974). Toward a theory of automatic information processing in reading. Cognitive Psychology, 6, 293-323.

[19] National Governors Association Center for Best Practices \& Council of Chief State School Officers (2012). Supplemental information for Appendix A of the Common Core State Standards for English language arts and literacy: New research on text complexity. Washington, DC: Authors. http://www.corestandards.org/assets/E0813_App endix_A_New_Research_on_Text_Complexity.pdf

[20] Klare, G.R. (1963). The measurement of readability. Ames, IA: Iowa State University Press.

[21] Crain, S. \& Shankweiler, D. (1988). Syntactic complexity and reading acquisition. In A. Davidson and G.M. Green (Eds.), Linguistic complexity and text comprehension: Readability issues reconsidered. Hillsdale, NJ: Erlbaum Associates.

[22] Foorman, B.R. (2009). Text difficulty in reading assessment. In E. F. Hiebert (Ed.), Reading more, reading better (pp. 231-250). New York: Guilford Press.

[23] McNamara, D.S., Kintsch, E., Songer, N.B., \& Kintsch, W. (1996). Are good texts always better? Interactions of text coherence, background knowledge, and levels of understanding in learning from text. Cognition and Instruction, 14(1), 1-43.

[24] Deane, P., Sheehan, K.M., Sabatini, J., Futagi, Y., \& Kostin, I. (2006). Differences in test structure and its implications for assessment of struggling readers. Scientific Studies of Reading, 19(3), 257-275. DOI: 10.1027/s1532799xssr1003 $-4$

[25] Hiebert, E.H. (2012). The common core's staircase of text complexity: Getting the size of the first step right. Reading Today, 29(3), 26-27.

[26] Mesmer, H.A.E., \& Hiebert, E.H. (2013). How far can third graders be "stretched"? Exploring the influence of text difficulty and length. Unpublished manuscript.

[27] Nelson, J., Perfetti, C., Liben, D., \& Liben, M. (2012). Measures of text difficulty: Testing their predictive value for grade levels and student performance. New York, NY: Student Achievement Partners. Retrieved from http://achie vethecore/content/upload/nelson_perfetti_liben_measures_ of_text_difficulty researchela.pdf

[28] Smith, III, M., \& Williamson, G.L. (2016). Aligning the K-12 academic journey with a postsecondary destination. The State Education Standard, 16(3), 14-18.

[29] Williamson, G.L. (2008). A text readability continuum for postsecondary readiness. Journal of Advanced Academics, 19(4), 602-632.

[30] Goodman, K. A. (1989). Whole language research: Foundations and development. The Elementary School Journal, 90, Special Issue: Whole Language. (Nov., 1989). Pp. 207-221.

[31] Lang, L. (2014). Learning to read with the whole language approach: The teacher's view. English Language Teaching, 7, 71-77.

[32] Perfetti, C. A. (1985). Reading ability. New York: Oxford University Press.

[33] Perfetti, C. A. (1988). Verbal efficiency in reading ability. In M. Daneman, G. E., Mackinnon, \& T. G. Waller (Eds.), Reading research: Advances in theory and practice (pp. 109-143). New York, NY: Academic Press

[34] Perfetti, C., \& Stafura, J. (2014). Word knowledge in a theory of comprehension. Scientific Studies of Reading, 18, 22-37. DOI: 10.1080/10888438.2013.827687

[35] Willingham, D. T. (2006). The usefulness of brief instruction in reading comprehension strategies. American Federation of Teachers, Winter, 30, 40-45, 50.

[36] Stage, S.A., \& Jacobsen, M.D. (2001). Predicting student success on a state-mandated performance-based assessment 
using oral reading fluency. School Psychology Review, 30(3), 407-419.

[37] Ganske, K. (2014). Word journeys: Assessment-guided phonics, spelling, and vocabulary instruction. New York: Guilford Press.

[38] Read, C. (1975). Children's categorization of speech sounds English. NCTE Committee on Research Report \#17. ERIC Clearinghouse on Languages and Linguistics, Arlington, VA, Reading and Communications Skills, Urbana, Il; National Council of Teachers of English, Urbana, Il.

[39] Henderson, E. H., \& Templeton, S. (1986). A developmental perspective of formal spelling instruction through alphabet, pattern, and meaning. The Elementary School Journal, 86, pp. 304-316.

[40] Torgesen, J.K., Wagner, R.K., \& Rashotte, C.A. (2014). Test of word reading efficiency (2nd ed.). Austin, TX: Pro-Ed.

[41] Graesser, A.C., McNamara, D.S., \& Kulikowich, J.M. (2011). Coh-Metrix: Providing multilevel analyses of text characteristics. Educational researcher, 40(5), 223-234. DOI: $10.3102 / 0013189 \mathrm{X} 11413260$

[42] Deno, S.L. (1985). Curriculum-based measurement: The emerging alternative. Exceptional Children, 52, 219-232.

[43] McGlinchey, M.T., \& Hixson, M.D. (2004). Using curriculum-based measurement to predict performance on state assessments in reading. School Psychology Review, 33, 193-203.

[44] Hirsch, E. D., Jr. (2003). Reading comprehension requires knowledge - of words and the world: Scientific insights into the fourth-grade slump and the nation's stagnant comprehension scores. American Educator, 10, 12-13, 16-22, 28-29, 44

[45] MetaMetrics (2000). The lexile framework for reading. Durham, NC: Author. Retrieved from www.lexile.com/abo ut-lexile/lexile-overview/

[46] MetaMetrics (2012). Linking the K-PREP reading with the Lexile Framework: A study to link the Kentucky performance rating for educational progress reading with the Lexile framework for reading. Durham, NC: MetaMetrics. Retrieved from http://education.ky.gov/aa/kt s/documents/k-preplexilelinkingstudy11-2012v2.pdf

[47] Hasbrouck, J., \& Tindal, G.A. (2006). Oral reading fluency norms: A valuable assessment for reading teachers. The Reading Teacher, 59(7), 636-644.

[48] Hoover, W.A., \& Gough, P.B. (1990). The simple view of reading. Reading and Writing: An Interdisciplinary Journal, $2,127-160$. 